\title{
The Effects of the PEM Fuel Cell Performance with the Waved Flow Channels
}

\author{
Yue-Tzu Yang, Kuo-Teng Tsai, and Cha'o-Kuang Chen \\ Department of Mechanical Engineering, National Cheng Kung University, Tainan 70101, Taiwan \\ Correspondence should be addressed to Chao-Kuang Chen; ckchen@mail.ncku.edu.tw
}

Received 12 October 2012; Accepted 24 December 2012

Academic Editor: Li Weili

Copyright (C) 2013 Yue-Tzu Yang et al. This is an open access article distributed under the Creative Commons Attribution License, which permits unrestricted use, distribution, and reproduction in any medium, provided the original work is properly cited.

\begin{abstract}
The objective of this study is to use a new style of waved flow channel instead of the plane surface channel in the proton exchange membrane fuel cell (PEMFC). The velocity, concentration, and electrical performance with the waved flow channel in PEMFC are investigated by numerical simulations. The results show that the waved channel arises when the transport benefits through the porous layer and improves the performance of the PEMFC. This is because the waved flow channel enhances the forced convection and causes the more reactant gas flow into the gas diffusion layer (GDL). The performance which was compared to a conventional straight gas flow channel increases significantly with the small gap size when it is smaller than 0.5 in the waved flow channel. The performance is decreased at the high and low velocities as the force convection mechanism is weakened and the reactant gas supply is insufficient. The pressure drop is increased as the gap size becomes smaller, and the wave number decreases. (gap size) $\delta>0.3$ has a reasonable pressure drop. Consequently, compared to a conventional PEMFC, the waved flow channel improves approximately $30 \%$ of power density.
\end{abstract}

\section{Introduction}

Proton exchange membrane (PEM) fuel cell is representative of the alternative power source for stationary applications. Many fundamental studies have been directed towards increasing our understanding of PEM fuel cells PEMFCs and their performance. The channel design also plays an important role in the PEMFC. The different shape can influence the reactant gas transport, the water management, and the performance of the fuel cell. The effects of the several different channel types such as the arrangements of serpentine channel, multiple channels in a parallel type, and interdigitated channels. have been studied in PEM fuel cells. Um and Wang $[1,2]$ developed a 3-D model to investigate the effects of oxygen, vapor, and fuel transport with straight and interdigitated channels. Nguyen [3] improves the masstransport rates of the reactants from the flow channels to the inner catalyst layers of the porous electrodes to reduce the electrode water flooding problem in the cathode of proton exchange membrane fuel cells by a nonconventional gas distribution design. Tüber et al. [4] investigated and compared the common serpentine and parallel flow fields. Both PEMFCs and Direct methanol fuel cell (DMFC) fractal flow fields show similar performance to parallel designs. The most stable and highest power output is reached with the serpentine flow field. He et al. [5] used interdigitated gas distributors in a PEM fuel cell. This characteristic increases transport rates of the reactants and products to and from the catalyst layers and reduces the amount of liquid water entrapped in the porous electrodes thereby minimizing electrode flooding. Weng et al. [6] studied 3-D numerical prediction in PEMFC. The simulation results revealed that serpentine and interdigitated flow patterns show a strong convection and a high mass transfer. The presentation of Nguyen et al. [7] revealed current distributions patterns that are significantly different from those obtained in studies assuming constant surface overpotential in the PEMFC with serpentine flow field channels. Hwang et al. [8] presented the transport phenomena on the cathodes with parallel and interdigitated gas distributors in PEMFC. The interdigitated gas distributor gives a higher average current density on the catalyst layer surface than that with the parallel gas distributor under the same mass flow rate and cathode overpotential. The limiting current density increased by $40 \%$ by using the interdigitated flow field design instead of the parallel one. Yan 


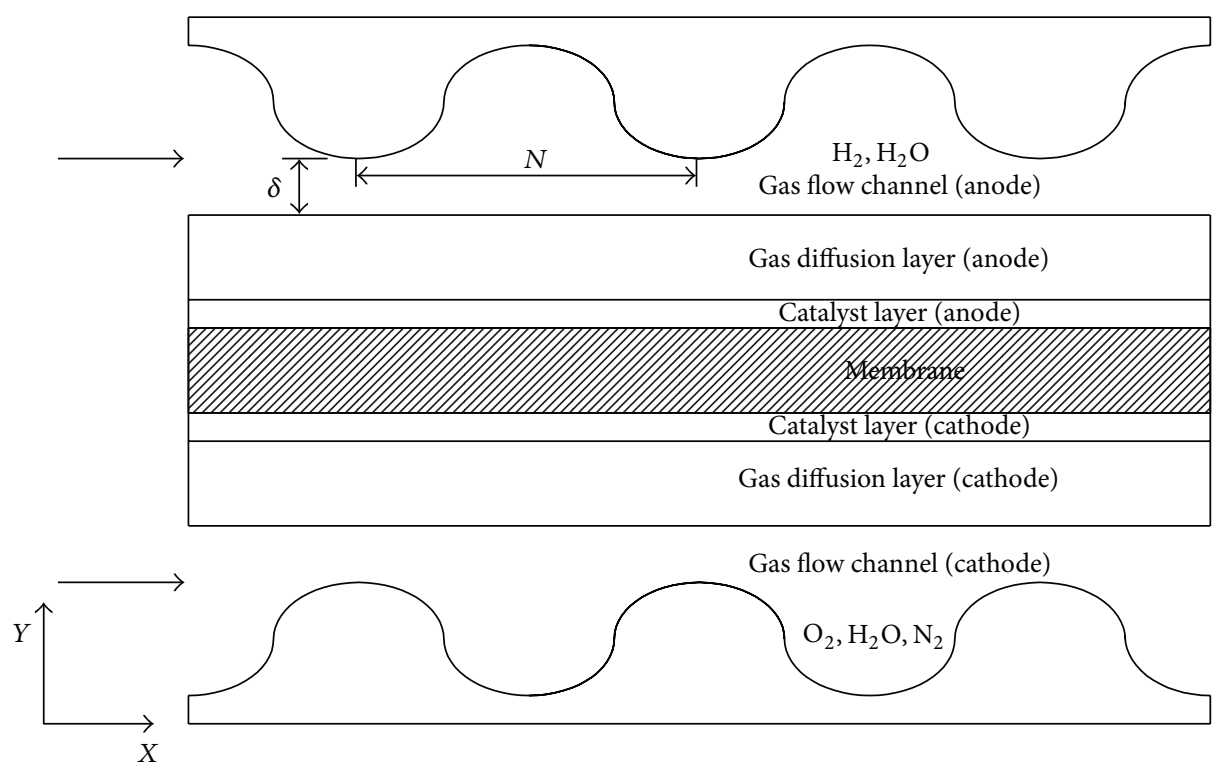

FIgURE 1: The physical model of the PEMFC with the waved gas flow channel.

et al. $[9,10]$ show that interdigitated flow field provides higher cell performance and remarkably reduces fuel consumption for efficient diffusion of the fuel gas to the diffuser layer than convectional flow field. The performance of the interdigitated flow field with flow area ratio of $50.75 \%$ is better than that with $66.75 \%$. Park and Li [11] study the cross flow in PEM fuel cell by numerical simulation and experiment. The results show that the pressure drop in a PEM fuel cell is significantly lower than that without cross flow. Wang et al. [12] investigate the transport phenomena in a 3-D model of PEMFC with parallel and interdigitated flow channel designs. The results show that the performance is independent of the flow channel design and operating parameters, and the performance for the interdigitated flow channel design occurs for a flow channel area ratio of 0.4 .

Liu et al. [13] studied the application of the baffle-blocked flow channels for the enhancement of reactant transport and cell performance of a proton exchange membrane fuel cell. The results showed that at low voltage conditions, the liquid water effect is especially significant and should be considered in the modeling. The cell performance can be enhanced, and the occurrence of mass transport loss can be delayed by raising the limiting current density considerably at a higher air velocity on the cathode side. Soong et al. [14] proposed a novel configuration of partially blocked fuel channel with baffle plates transversely inserted in the channel. The numerical simulation showed designs with the baffle gap ratio no smaller than 0.1 , number of baffle plates $N=3-5$, and the GDL porosity around 0.7 seemed quite appropriate. Kuo and Chen [15-17] reported on novel composite material for the bipolar of proton exchange membrane fuel cells by wave-like channel design. The characterization of the behavior of a single proton exchange membrane fuel cell was discussed with variation of the values of six operation variables by Santarelli and Torchio [18]. The results showed that a combined effect of humidification and operating
TABLE 1: Geometric and physical parameters in PEMFC model.

\begin{tabular}{lc}
\hline Quantity & Value \\
\hline Gas channel depth & $0.5 \mathrm{~mm}$ \\
Gas channel width & $1.0 \mathrm{~mm}$ \\
Gas channel length & $50 \mathrm{~mm}$ \\
Gas diffusion layer thickness & $0.25 \mathrm{~mm}$ \\
Catalyst thickness & $0.025 \mathrm{~mm}$ \\
Membrane thickness & $0.25 \mathrm{~mm}$ \\
Porosity of gas diffusion layer & 0.4 \\
Porosity of catalyst layer & 0.28 \\
Permeability of gas diffusion layer & $1.76 \times 10^{-11} \mathrm{~m}^{2}$ \\
Permeability of catalyst layer & $1.76 \times 10^{-11} \mathrm{~m}^{2}$ \\
Permeability of membrane layer & $1.18 \times 10^{-18} \mathrm{~m}^{2}$ \\
Tortuosity of gas diffusion layer & 1.5 \\
Tortuosity of catalyst layer & 1.5 \\
Electronic conductivity of gas diffusion layer & $53 \mathrm{~S} / \mathrm{m}$ \\
Electronic conductivity of catalyst layer & $53 \mathrm{~S} / \mathrm{m}$ \\
Inlet temperature & $353 \mathrm{~K}$ \\
Operation pressure & $1 \mathrm{~atm}$ \\
Anode fuel & $\mathrm{H}_{2}, \mathrm{H}_{2} \mathrm{O}$ \\
Cathode fuel & $\mathrm{N}_{2}, \mathrm{O}_{2}$ \\
Relative humidity of the anode & $100 \%$ \\
\hline
\end{tabular}

pressure was observed. Hu et al. [19, 20] studied 3-D and twophase flow mathematical model for PEM fuel cell, and the humidification is important for an interdigitated flow field to acquire a much better performance than a conventional flow field. Hsieh et al. [21] experimentally studied different flow field configurations with different operating parameters on micro PEM fuel cell. It was found that among the three 
TABLE 2: Analytical formulae for source terms in governing equations.

\begin{tabular}{lcccc}
\hline & $S_{u}$ & $S_{v}$ & $S_{c}$ & - \\
\hline Flow channel & 0 & 0 & - & $S_{\phi}$ \\
Diffusion layer & $-\frac{v \varepsilon^{2}}{k_{p}} u-\frac{\varepsilon_{\text {eff }}^{3} C_{F} \rho u}{\sqrt{k_{p}}} \sqrt{u^{2}+v^{2}}$ & $-\frac{v \varepsilon^{2}}{k_{p}} v-\frac{\varepsilon_{\text {eff }}^{3} C_{F} \rho v}{\sqrt{k_{p}}} \sqrt{u^{2}+v^{2}}$ & 0 & 0 \\
Catalyst layer & $-\frac{v \varepsilon^{2}}{k_{p}} u-\frac{\varepsilon_{\text {eff }}^{3} C_{F} \rho u}{\sqrt{k_{p}}} \sqrt{u^{2}+v^{2}}$ & $-\frac{v \varepsilon^{2}}{k_{p}} v-\frac{\varepsilon_{\text {eff }}^{3} C_{F} \rho v}{\sqrt{k_{p}}} \sqrt{u^{2}+v^{2}}$ & $\mathrm{H}_{2}:-\frac{j_{a}}{2 F C_{a}}, \mathrm{O}_{2}:-\frac{j_{c}}{4 F C_{c}}, \mathrm{H}_{2} \mathrm{O}: \frac{j_{c}}{2 F C_{c}}$ & $j$ \\
& $-\frac{v \varepsilon^{2}}{k_{p}} u-\frac{\varepsilon_{\mathrm{eff}}^{2} C_{F} \rho u}{\sqrt{k_{p}}} \sqrt{u^{2}+v^{2}}$ & $-\frac{v \varepsilon^{2}}{k_{p}} v-\frac{\varepsilon_{\mathrm{eff}}^{2} C_{F} \rho v}{\sqrt{k_{p}}} \sqrt{u^{2}+v^{2}}$ & $\frac{Z F}{R T} D_{k, \text { eff }, H^{+}} \cdot C_{H^{+}}\left(\frac{\partial^{2} \phi}{\partial x^{2}}+\frac{\partial^{2} \phi}{\partial y^{2}}\right)$ & 0 \\
& $+\frac{k_{p}}{v} Z_{f} C_{H}+F \cdot \nabla \phi \frac{\partial u}{\partial x}$ & $+\frac{k_{p}}{v} Z_{f} C_{H}+F \cdot \nabla \phi \frac{\partial u}{\partial x}$ & & \\
\hline
\end{tabular}

flow patterns considered, significant improvements can be reached with specified flow geometry.

The major objectives of this study focus on the shape of the flow channel by numerical simulation. This study performs numerical simulations to investigate the influence of the forced convection effect $[13,14]$ for waved flow channels. The waved flow channel is used, and the effects of the performance are discussed for velocity in the cathode channel, the waved number, and the gap size between the bipolar plate and membrane electrode assembly (MEA). The validity of the numerical model is confirmed by comparing the results obtained for the electrical performance of the PEMFC with the experimental results presented by $\mathrm{Hu}$ et al. [20].

\section{Governing Equation}

The simulations performed in this study are based on a steady-state, single-phase, multispecies, two-dimensional mass transfer model of a PEMFC. The physical domain is shown in Figure 1. As shown, the fuel cell comprises anode and cathode flow channels with waved profiles, two gas diffusion layers made of a porous material, two catalyst layers, and a proton exchange membrane. The operating pressure and the temperature are $1 \mathrm{~atm}$ and $353 \mathrm{~K}$, respectively. The simulations assume that the anode is supplied with humidified hydrogen with a mass fraction of $0.70 / 0.30 \mathrm{H}_{2} / \mathrm{H}_{2} \mathrm{O}$. The cathode side is fed with saturated air with a mass fraction of $0.21 / 0.79 \mathrm{O}_{2} / \mathrm{N}_{2}$. The geometry and physical parameters are given in Table 1. The following additional assumptions are also made.

(1) The simulation is steady-state condition and 2-D.

(2) The gases are all assumed to be ideal gas mixtures, and the water is treated as vapor.

(3) The flow in the channel is considered laminar.

(4) The gas diffusion layer, the catalyst layer, and the membrane are all isotropic and homogeneous and are characterized by high permeability and a uniform porosity.

(5) The electrochemical reaction is governed by ButlerVolmer kinetics [20, 22].

(6) The membrane is impervious to the reactant gases.
(7) The fuel cell geometry is periodic in the $x$-axis direction.

(8) The effect of gravity is negligible.

(9) The properties are constant.

PEMFCs with various gas flow channel configurations have been presented in the literature. In general, the aim of the these different designs is to add the area of the reaction surface exposed to the oxygen and hydrogen gas streams and to provide a route for the liquid water produced during the catalytic reaction to exit the fuel cell. The waved gas flow channel considered in this study has the additional function of enhancing the gas velocity in the vertical direction in order to improve the efficiency of the catalytic process.

The governing equations in the flow channel, gas diffusion layer, catalyst layer, and membrane are as follows:

continuity equation:

$$
\frac{\partial u}{\partial x}+\frac{\partial v}{\partial y}=0
$$

momentum equations:

$$
\begin{aligned}
& \varepsilon_{\text {eff }}\left(u \frac{\partial u}{\partial x}+v \frac{\partial u}{\partial y}\right)=-\frac{\varepsilon_{\text {eff }}}{\rho} \frac{\partial P}{\partial x}+v \varepsilon_{\text {eff }}\left(\frac{\partial^{2} u}{\partial x^{2}}+\frac{\partial^{2} u}{\partial y^{2}}\right)+S_{u} \\
& \varepsilon_{\text {eff }}\left(u \frac{\partial v}{\partial x}+v \frac{\partial v}{\partial y}\right)=-\frac{\varepsilon_{\text {eff }}}{\rho} \frac{\partial P}{\partial y}+v \varepsilon_{\text {eff }}\left(\frac{\partial^{2} v}{\partial x^{2}}+\frac{\partial^{2} v}{\partial y^{2}}\right)+S_{v}
\end{aligned}
$$

species conservation equation:

$$
\varepsilon_{\text {eff }}\left(u \frac{\partial C_{k}}{\partial x}+v \frac{\partial C_{k}}{\partial y}\right)=D_{k, \text { eff }}\left(\frac{\partial^{2} C_{k}}{\partial x^{2}}+\frac{\partial^{2} C_{k}}{\partial y^{2}}\right)+S_{c} ;
$$

charge conservation equation:

$$
\varepsilon_{\text {eff }}\left(u \frac{\partial \phi_{e}}{\partial x}+v \frac{\partial \phi_{e}}{\partial y}\right)=-S_{\phi} .
$$

The source terms, $S_{u}, S_{v}, S_{c}$, and $S_{\phi}$, are presented in Table 2 . In these formulae, the parameters $\varepsilon_{\mathrm{eff}}, C_{F}, k_{p}$, and $Z_{f}$ 


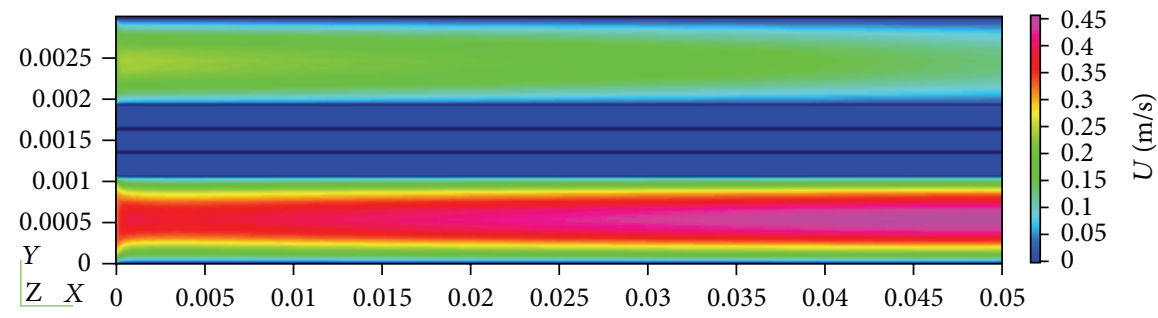

(a)

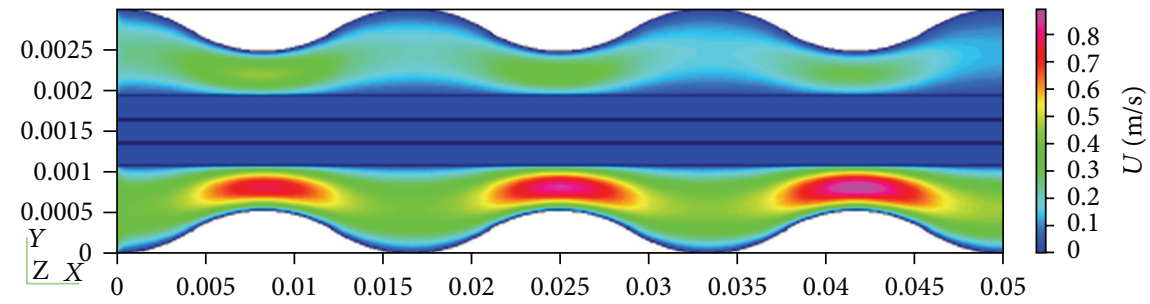

(b)

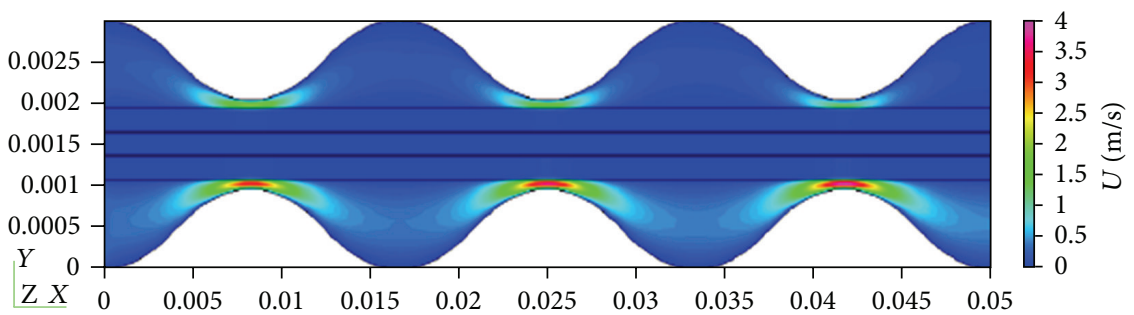

(c)

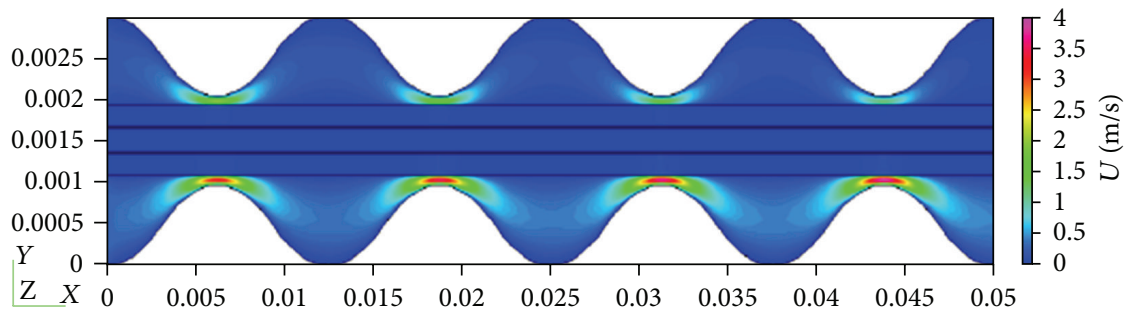

(d)

FIgURE 2: The $x$-direction velocity field in the PEMFC.

denote the effective porosity, the quadratic drag factor, the permeability, and the valence of the species, respectively. The effective porosity is equal to 1 in the flow channel. Furthermore, $D_{k \text {,eff }}=D_{k} \varepsilon^{\tau_{i}}$ represents the effective diffusion coefficient of the $k$ th component of the reactant fuel, and the diffusivities are corrected using the Bruggemann correction formula [7].

In the PEMFC, the generation/consumption of the chemical species and the charge transfer are restricted to the catalyst layer. Therefore, the source terms in (3) and (4) can be implemented based on electrochemical kinetics; that is,

$$
\begin{gathered}
S_{\mathrm{H}_{2}}=-\frac{j_{\text {anode }}}{2 F C_{a}}, \\
S_{\mathrm{O}_{2}}=-\frac{j_{\text {cathode }}}{4 F C_{c}}, \\
S_{\mathrm{H}_{2} \mathrm{O}}=-\frac{j_{\text {cathode }}}{2 F C_{c}},
\end{gathered}
$$

where $j$ denotes the transfer current density and is derived from the following Butler-Volmer kinetics [20, 22] expressions:

$$
\begin{aligned}
& j_{a}=j_{a, \text { ref }}\left(\frac{C_{\mathrm{H}_{2}}}{C_{\mathrm{H}_{2}, \text { ref }}}\right)^{1 / 2} \times\left[\exp \left(\frac{\alpha_{a} F}{R T} \eta_{\text {act }}\right)-\exp \left(-\frac{\alpha_{c} F}{R T} \eta_{\text {act }}\right)\right], \\
& j_{c}=j_{c, \text { ref }}\left(\frac{C_{\mathrm{O}_{2}}}{C_{\mathrm{O}_{2}, \text { ref }}}\right)^{1 / 2} \times\left[\exp \left(\frac{\alpha_{a} F}{R T} \eta_{\text {act }}\right)-\exp \left(-\frac{\alpha_{c} F}{R T} \eta_{\text {act }}\right)\right],
\end{aligned}
$$

where $\eta_{\text {act }}$ is the surface over potential and is defined as

$$
\eta_{\mathrm{act}}=\varphi_{a, c}-\varphi_{m}-V_{\mathrm{OC}}
$$

in which $\varphi_{a, c}$ and $\varphi_{m}$ denote the potentials of the carbon phase and the membrane phase, respectively, in the catalyst layer, and $V_{\mathrm{OC}}$ is the reference open-circuit potential of the electrode. 


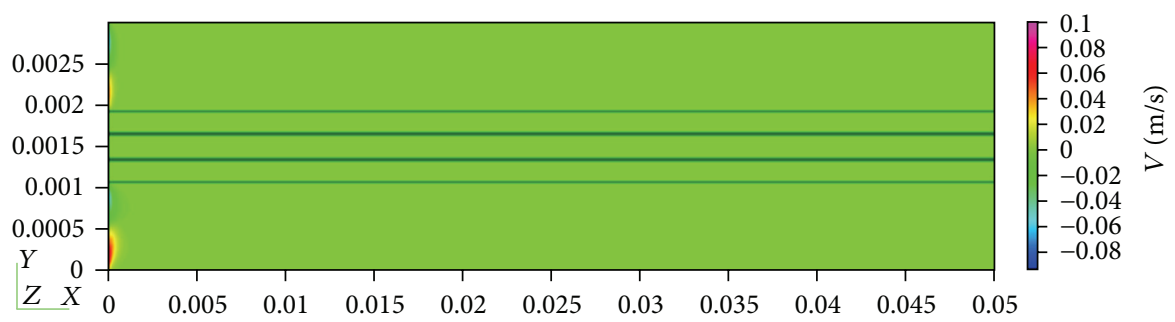

(a)

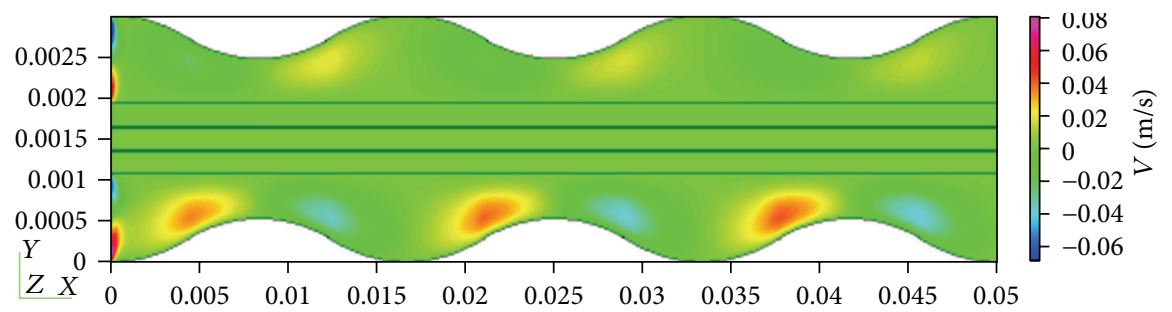

(b)

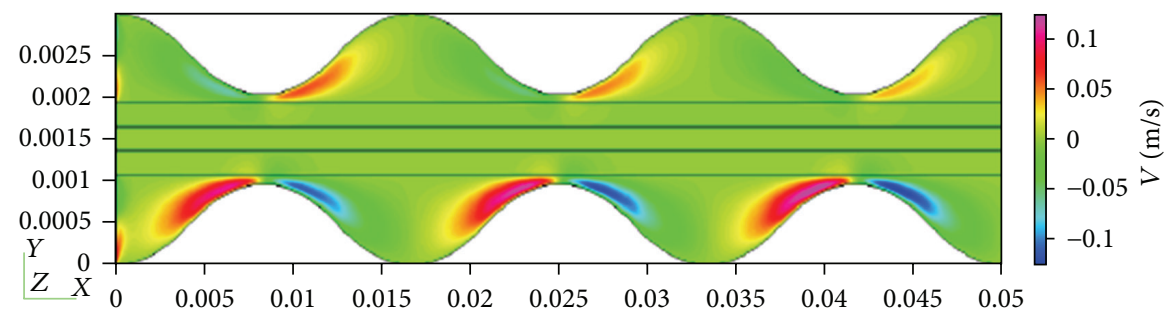

(c)

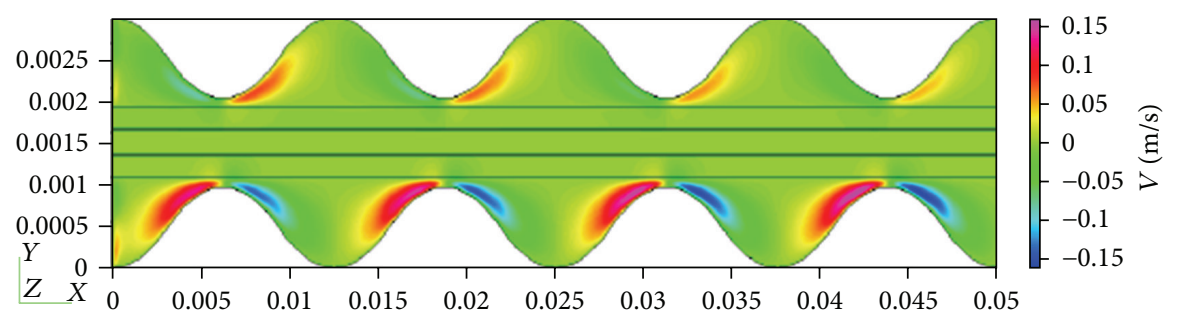

(d)

FIgure 3: The $y$-direction velocity field in the PEMFC.

The phase potential equation for the potential and current profiles is given by

$$
\frac{\partial}{\partial x}\left(\sigma_{m} \frac{\partial \Phi}{\partial x}\right)+\frac{\partial}{\partial y}\left(\sigma_{m} \frac{\partial \Phi}{\partial y}\right)=S_{j},
$$

where $\Phi$ is the phase potential function, and $\sigma_{m}$ is the membrane conductivity, which was proposed by Springer et al. [23] as

$$
\sigma_{m}(T)=\sigma_{m}^{\mathrm{ref}} \exp \left[1268\left(\frac{1}{303}-\frac{1}{T}\right)\right],
$$

where $\sigma_{m, \text { ref }}$ is the reference conductivity of the membrane and is given by

$$
\begin{gathered}
\sigma_{m}^{\mathrm{ref}}=0.005139 \lambda-0.00326, \\
\lambda=\left\{\begin{array}{cc}
0.043+17.81 \cdot a-39.85 \cdot a^{2}+36.0 \cdot a^{3} & \text { for } 0<a \leq 1 \\
14+1.4 \cdot(a-1) & \text { for } 1 \leq a \leq 3
\end{array}\right\},
\end{gathered}
$$

in which $a$ is the water activity and is defined as

$$
a=\frac{x_{\mathrm{H}_{2} \mathrm{O}} P}{P_{\text {sat }}} \text {. }
$$

In (11), the saturation pressure varies with the temperature and can be determined directly from thermodynamic tables or from the following empirical expression:

$$
P_{\text {sat }}=10^{-2.1794+0.02953 T-9.1837 \times 10^{-5} T^{2}+1.4454 \times 10^{-7} T^{3}} .
$$

\section{Boundary Conditions}

The governing equations for the current PEMFC model are elliptic, partial differential equations, and hence, boundary conditions are required for all of the boundaries in the computational domain. Due to the conjugated nature of the current problem, the gas flow channel surfaces are included within the solution domain and are treated as a particular type of fluid. 


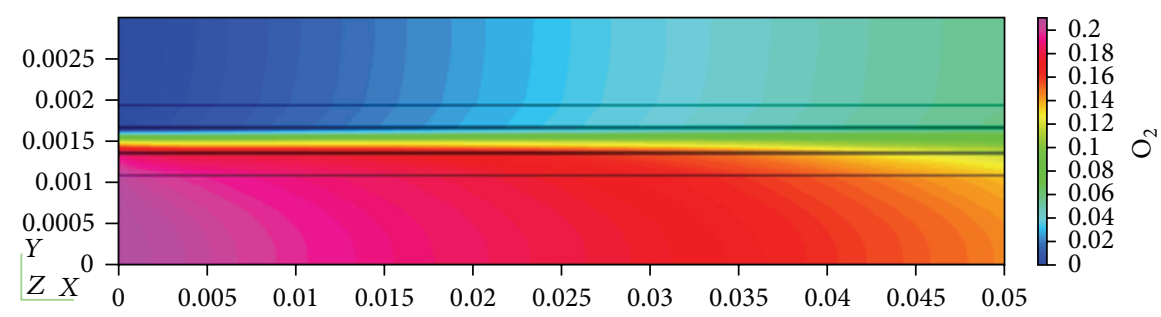

(a)

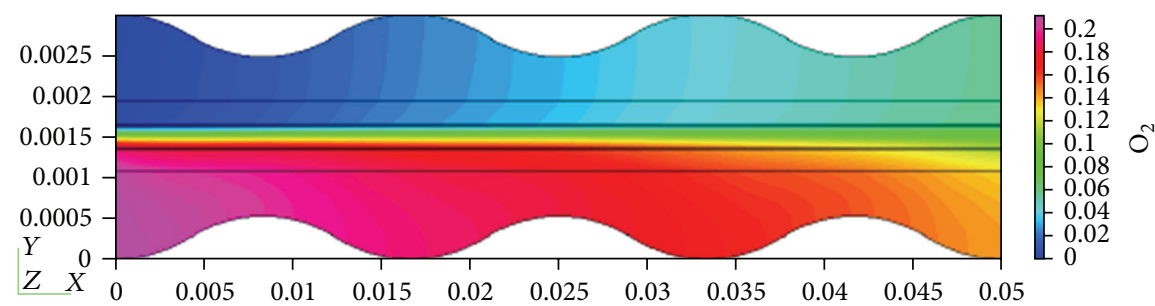

(b)

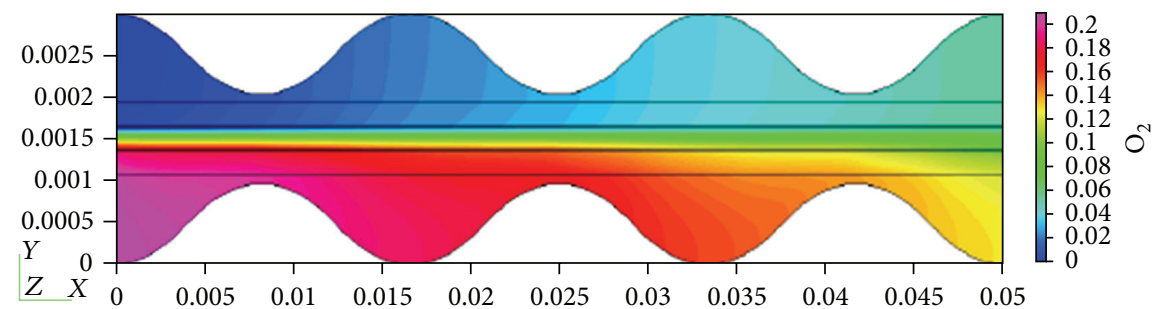

(c)

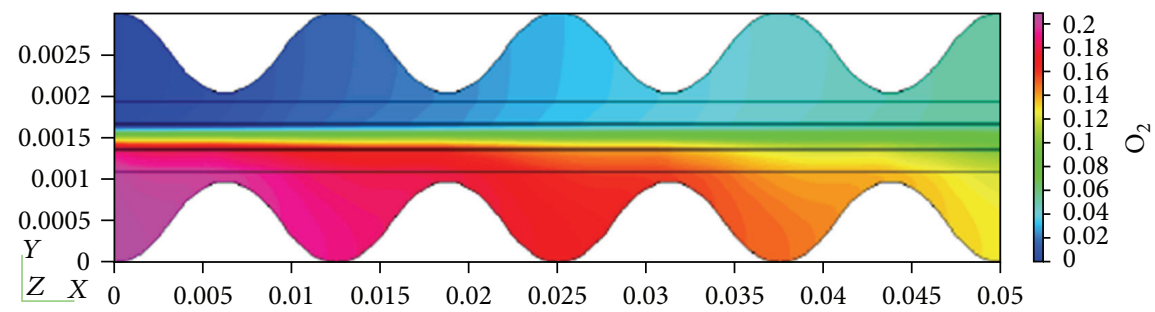

(d)

FIGURE 4: Oxygen concentration distribution in waved gas flow channel for constant cell voltage of $0.6 \mathrm{~V}$.

The boundary conditions are as follows:

(1) Gas flow channel: anode inlet:

$$
\begin{gathered}
u=u_{\mathrm{in}}, \quad v=0, \\
C_{\mathrm{H}_{2}}=C_{\mathrm{H}_{2}, \mathrm{in}}^{c}, \quad C_{\mathrm{N}_{2}}=C_{\mathrm{N}_{2}, \mathrm{in}}^{c} ;
\end{gathered}
$$

cathode inlet:

$$
\begin{gathered}
u=u_{\mathrm{in}}, \quad v=0 \\
C_{\mathrm{O}_{2}}=C_{\mathrm{o}_{2}, \mathrm{in}}^{c}, \quad C_{\mathrm{N}_{2}}=C_{\mathrm{N}_{2}, \mathrm{in}}^{c}
\end{gathered}
$$
layer:

interface between gas flow channel walls and catalyst

$$
u=v=\frac{\partial C_{k}}{\partial x}=0
$$

(2) Gas flow channel outlet:

$$
\frac{\partial u}{\partial x}=\frac{\partial v}{\partial x}=0
$$

(3) Upper surface: anode gas channel:

$$
u=v=0
$$

(4) Lower surface:

cathode gas channel:

$$
u=v=0 .
$$

\section{Numerical Method}

A nonuniform grid system with a large concentration of nodes at the regions of steep gradients, such as those close 


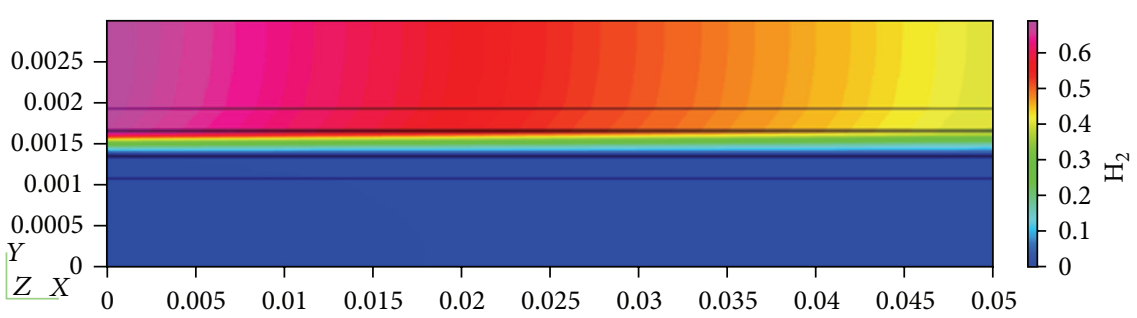

(a)

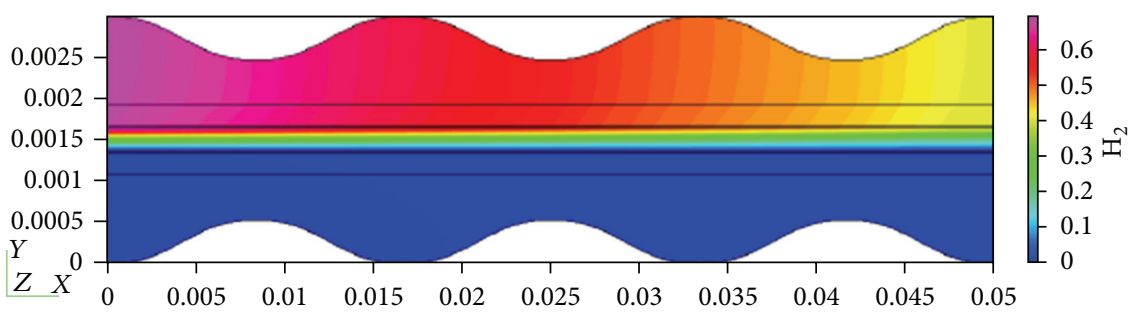

(b)

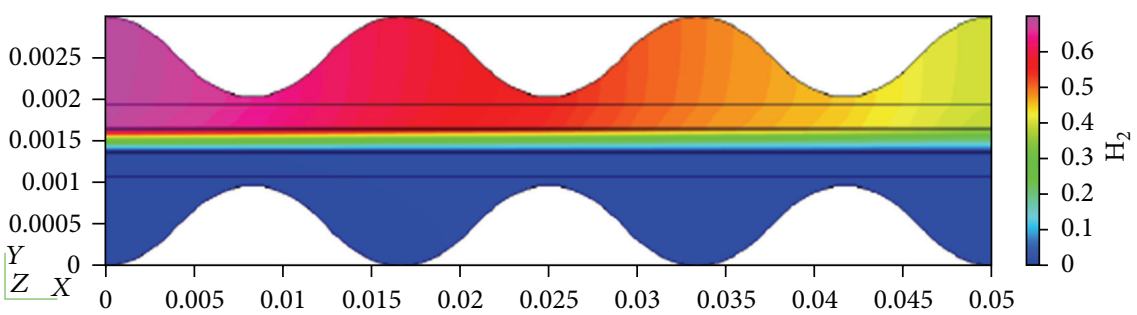

(c)

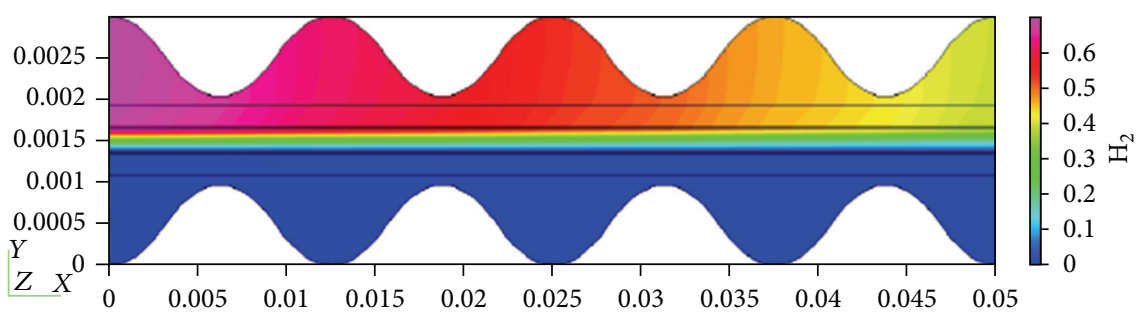

(d)

FIGURE 5: Hydrogen concentration distribution in waved gas flow channel for constant cell voltage of $0.6 \mathrm{~V}$.

to the step, walls near the corners, and porous layer, was employed. The simulation discretizes the governing equation using the finite-volume semi-implicit method for pressurelinked equations consistent (SIMPLEC) method [24]. A parametric study was performed to identify a suitable grid mesh capable of generating accurate representations of the properties near the walls so as to provide detailed insights into the electrochemical reaction and mass transport phenomena in the PEMFC. In the case $(\delta=0.5$ and $N=3)$, the velocity and concentration profiles in the interface between the flow channel and gas diffusion layer are corresponded with the grid of $144 \times 68,180 \times 84$, and $216 \times 100$. Therefore, the $180 \times 84$ is chosen. By the same way, the other cases are checked. The iterative computations were terminated once the value of the residues fell to less than $10^{-6}$. The computations were performed using a $\mathrm{PC}$ with a $3.0 \mathrm{GHz}$ Intel Pentium 4 CPU, 1 GB DDR RAM, and Windows XP operating system.

\section{Results and Discussions}

The numerical model used describes the different shapes of the gas flow channel. This research studied the number of the waved, the gap size of the waved, the different inlet velocity of the gas channel in PEMFC, the velocity field, concentration transport, and the performance of the PEMFC.

5.1. Velocity Field. The transport phenomenon plays an important role for the characteristics in the PEMFC, and the flow velocity is a fundamental effect on the gas transport. Figures 2(a)-2(d) show the axial flow velocity profile $(x-$ direction) in the straight and waved flow channels for laminar flow with an operating potential of $0.6 \mathrm{~V}$, the air flow inlet velocity of $0.3 \mathrm{~m} / \mathrm{s}$, and the hydrogen flow inlet velocity of $0.2 \mathrm{~m} / \mathrm{s}$. Figures $2(\mathrm{a})-2(\mathrm{c})$ represent the $x$-direction velocity at the straight, $\delta=0.5$, and 0.1 in the gas flow channel. It shows that the waved flow channel helps more gas flow into 


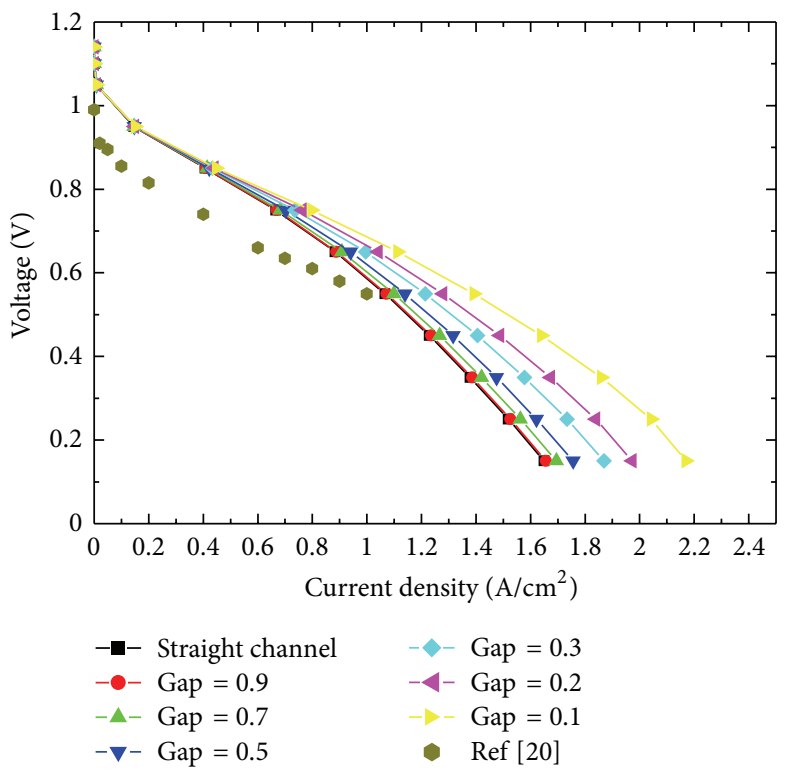

(a)

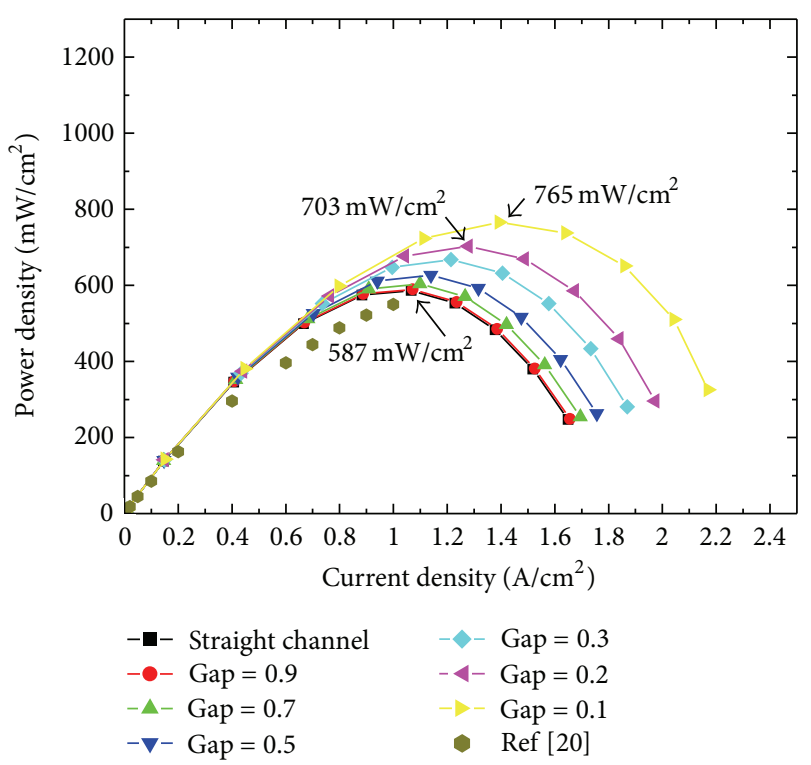

(b)

Figure 6: (a) Polarization curve and (b) power density curve in the waved gas flow channel for the gap's sizes.

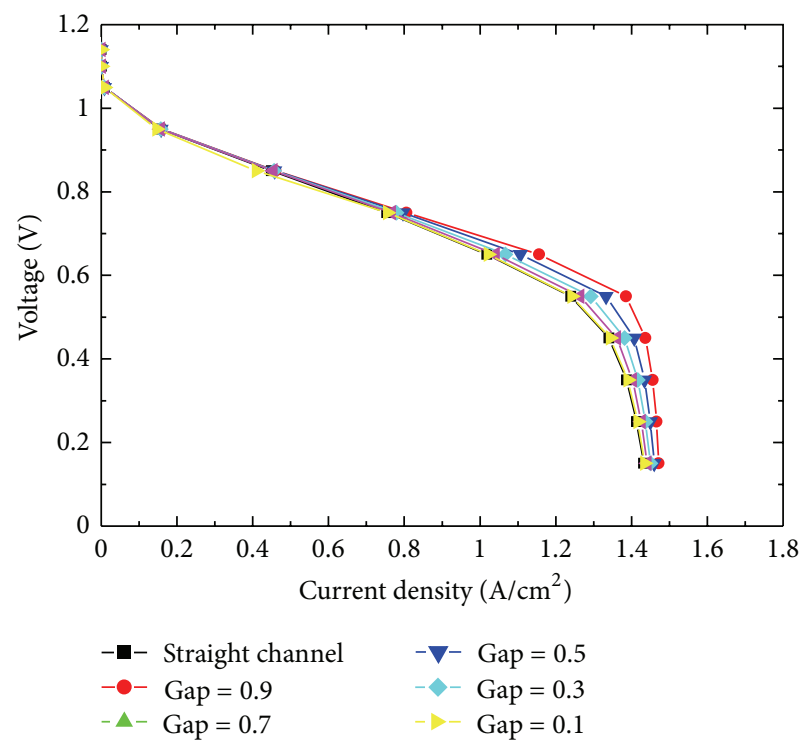

(a)

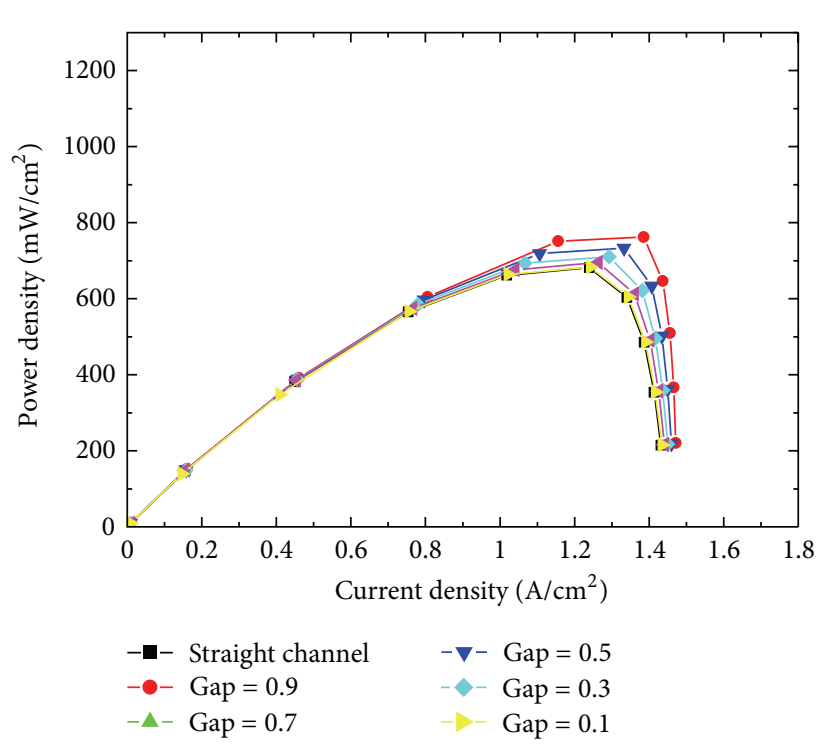

(b)

Figure 7: (a) Polarization curve and (b) power density curve in the waved gas flow channel for the gap's sizes at lower velocity.

the GDL, and the effect becomes significant following the decay of the gap size. The velocity along the axial direction varies more acutely in the waved channel than in the straight channel. The maximum axial velocity in the straight channel is $0.4583 \mathrm{~m} / \mathrm{s}$ of the cathode channel, but in the waved channel with $\delta=0.9$ it is $4.034 \mathrm{~m} / \mathrm{s}$. Figure 2(d) is the waved flow channel with $N=4$ and $\delta=0.1$. We can find that the axial flow velocity is similar and the total area with higher velocity is almost equivalent. Figures 3(a)-3(d) show the distribution of the $y$-direction velocity in the straight and waved flow channels in the same conditions as Figure 2. The vertical velocity becomes rapid in the waved flow channel and is uniform in the straight flow channel. Figures 3(b) and 3(c) display that the $y$-direction velocity increases more in the GDL, and the maximum velocity in the GDL is about $0.02 \mathrm{~m} / \mathrm{s}$ in Figure 3(c). If the waved number adds from 3 to 4, we observe that the maximum vertical velocity increases, and the vertical velocity near GDL is alike. The velocity in the waved channel is higher than that in the straight channel because the nozzle-type effect accelerates flow. The nozzletype effect is disregarded for the large gap size which is greater than 0.5. Adding the waved number can add to the maximum 


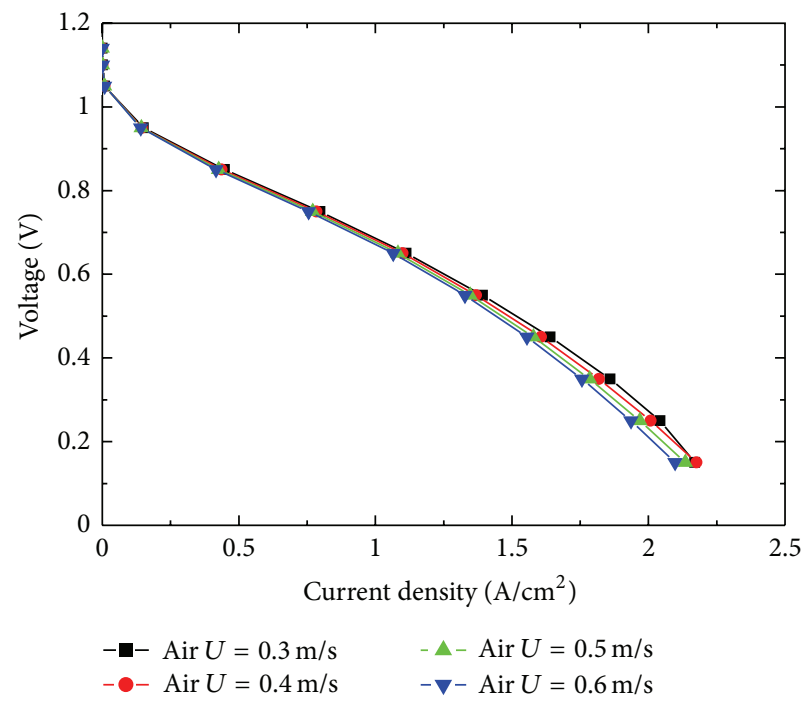

(a)

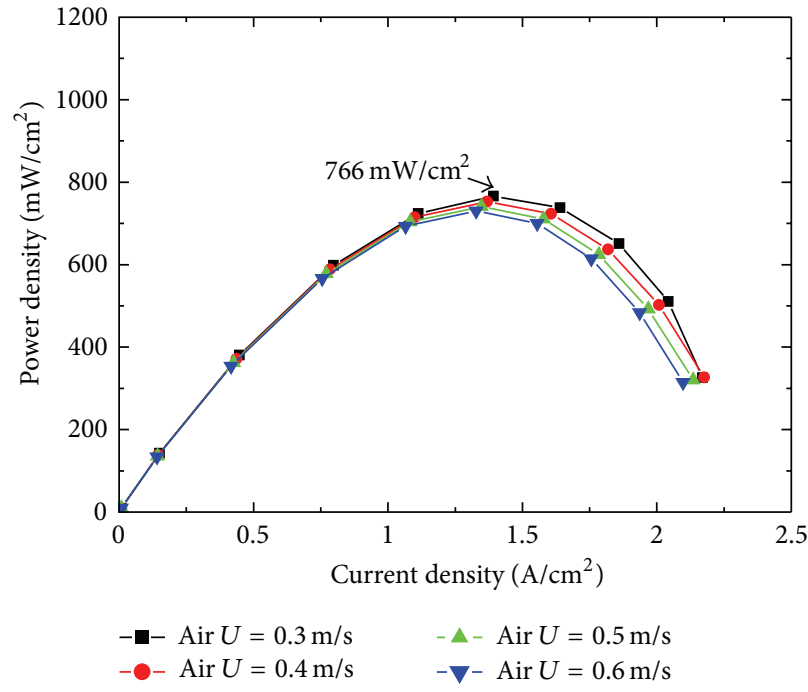

(b)

Figure 8: (a) Polarization curve and (b) power density curve in the waved gas flow channels for various inlet velocity conditions in the cathode channel (3-wave gap $=0.1)$.

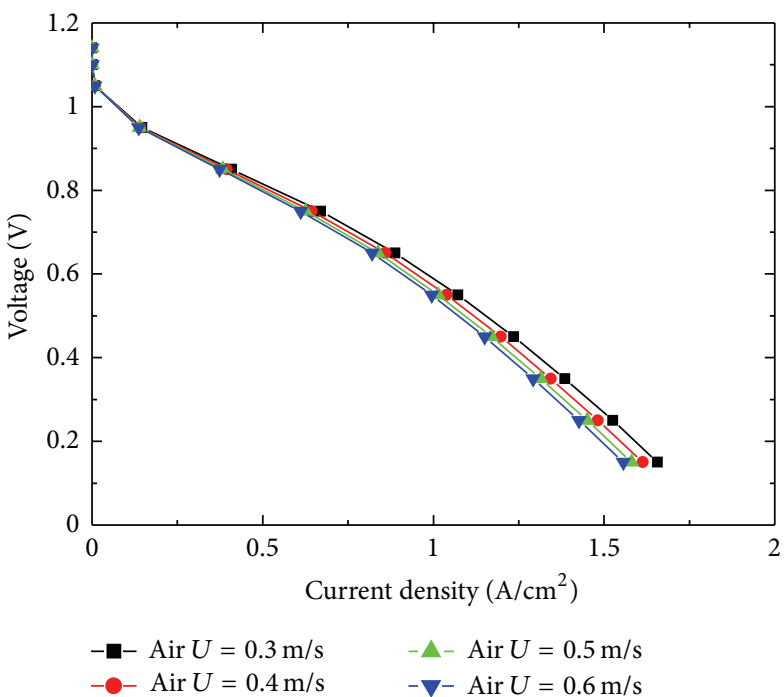

(a)

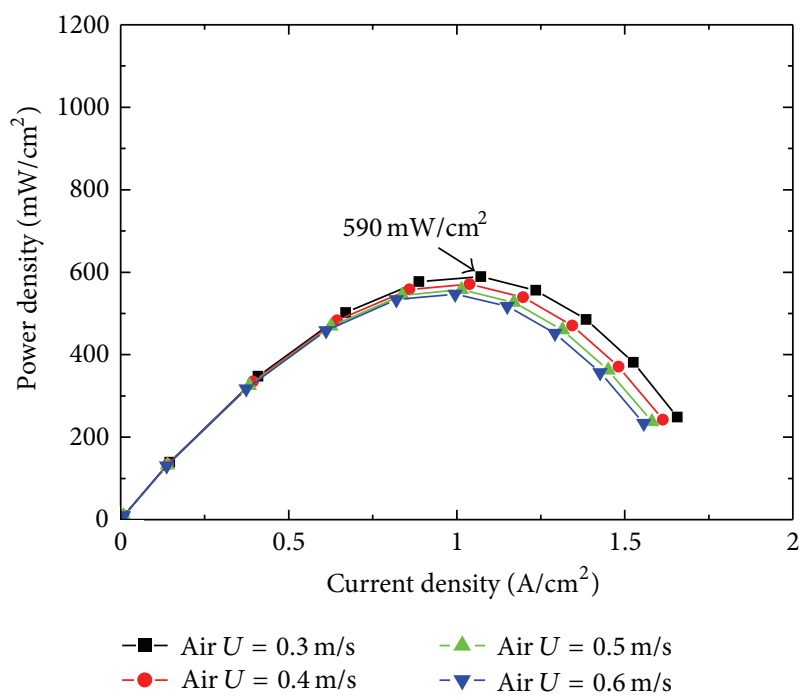

(b)

Figure 9: (a) Polarization curve and (b) power density curve in the waved gas flow channels for various inlet velocity conditions in the cathode channel (3-wave gap $=0.9)$.

vertical velocity, but the vertical velocity and the maximum axial velocity have no additional effect. Hence, the waved flow channel induces a strong convection force along the reaction surface. The mechanism increases the reactant gases to the catalyst layers and drives out the reaction products by the reactant processes. Therefore, the performance of the fuel cell is significantly improved by the waved flow channel in lower gap size.

5.2. Concentration Distribution. Figures 4 and 5 show the oxygen and hydrogen concentrations in the waved and straight gas flow channels. The over potential is $0.6 \mathrm{~V}$, and the contour indicates the molar concentration of the two gases. The oxygen concentration reduces slightly along the axial direction, as in Figures 4(a)-4(d). Conspicuously, the oxygen concentration varies rapidly near the reactant surface. The contour in the waved flow channel has a greater variation than that in the straight flow channel. The phenomenon is the result of the forced convection effect caused by the geometric change, and more reactant gases flow into the catalyst layer. The concentration field varies acutely comparing Figures $4(\mathrm{~b})$ and $4(\mathrm{c})$ because the small gap size causes the stronger convection flow. As the gap size becomes smaller, the oxygen concentration consumption becomes serious. 


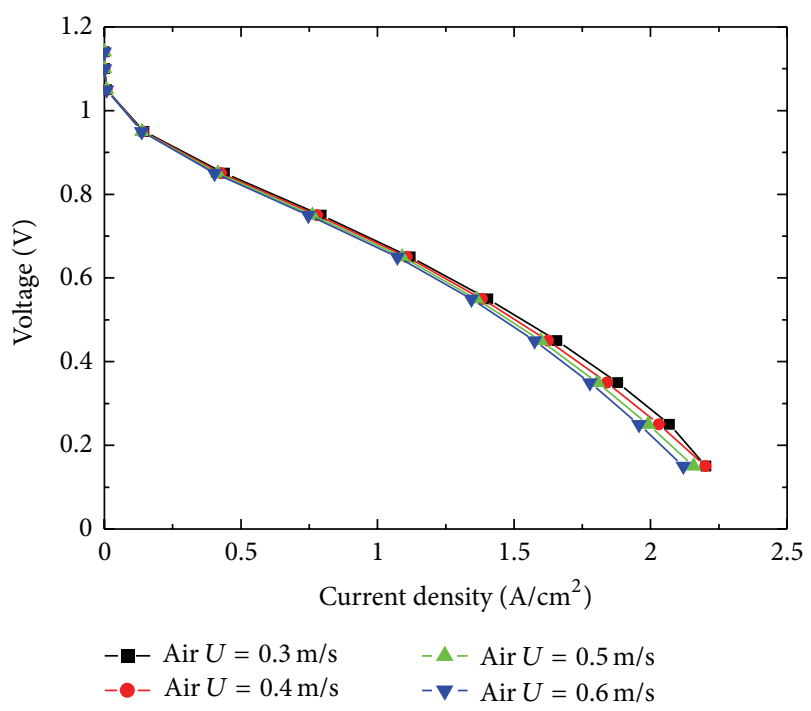

(a)

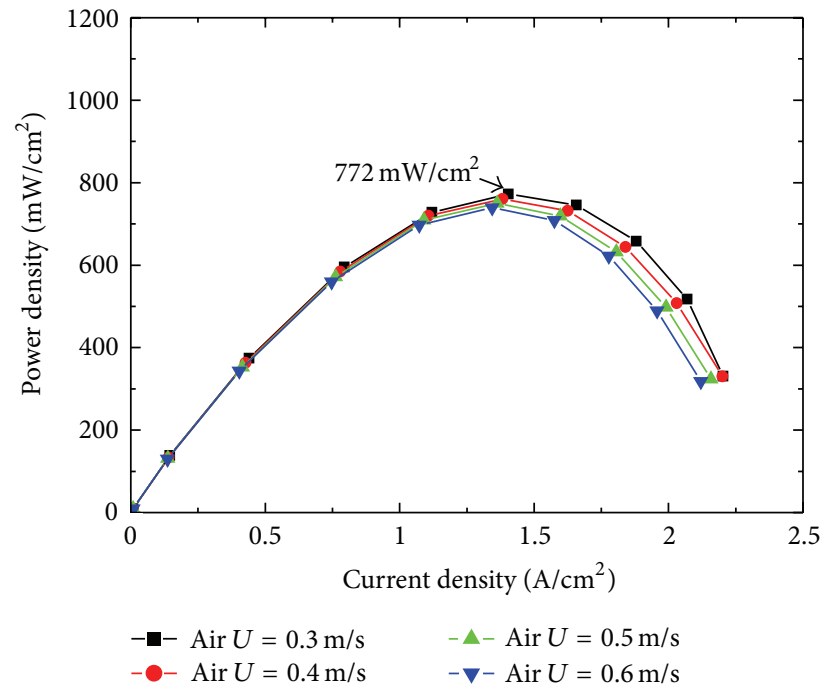

(b)

Figure 10: (a) Polarization curve and (b) power density curve in the waved gas flow channels for various inlet velocity conditions in the cathode channel. (6-wave gap $=0.1)$.

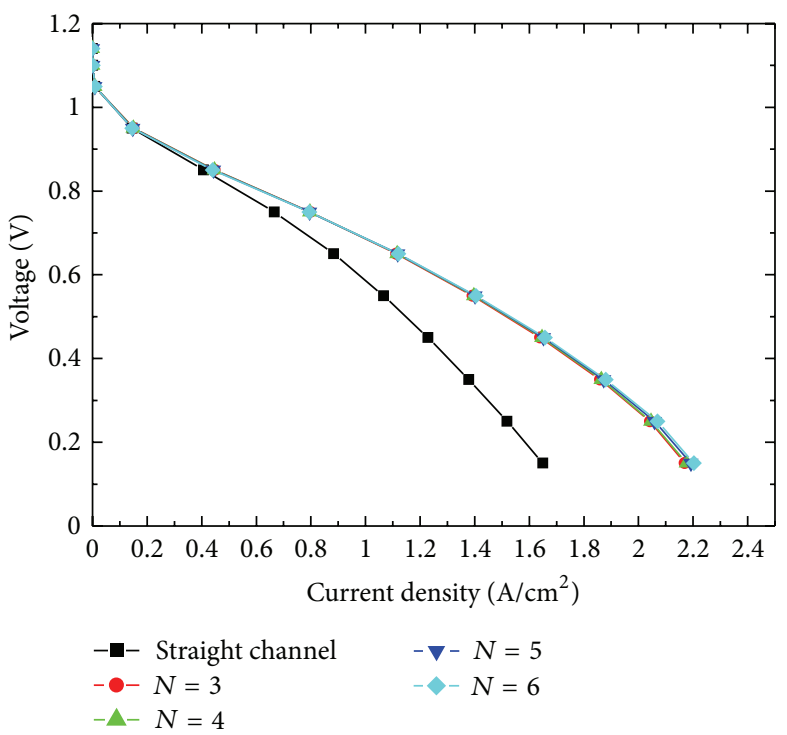

(a)

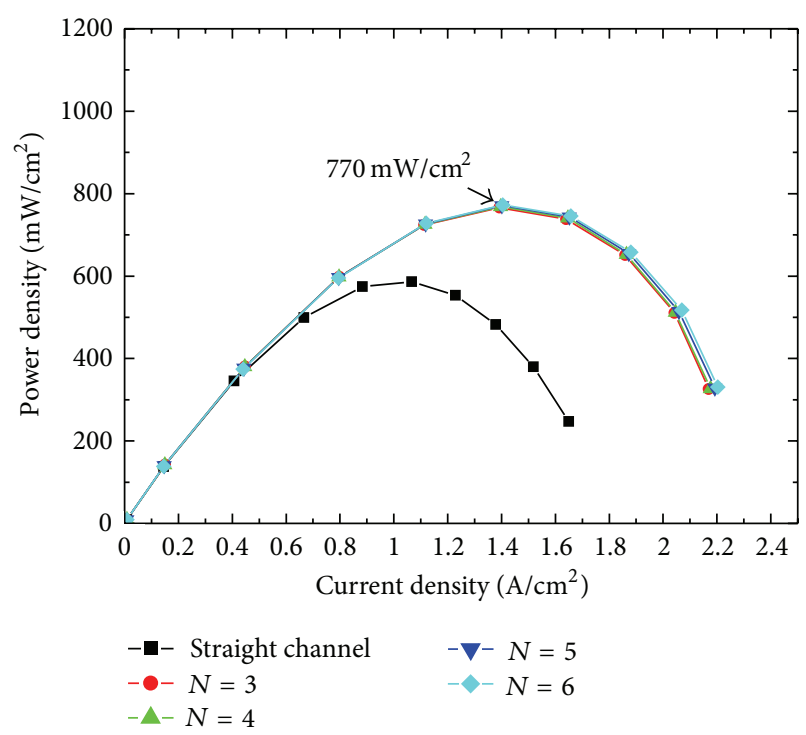

(b)

FIGURE 11: (a) Polarization curve and (b) power density curve in the waved gas flow channel for the different wave numbers at the higher velocity.

This phenomenon appears to mean that the reactant in the catalyst layer grows up and the residual decreases. The wave number in the flow channel in Figures 4(c) and 4(d) has no obvious difference in the oxygen concentration. Figures 5(a)-5(d) represent the hydrogen distribution in the channel. The result shows that the hydrogen concentration varies gently compared to the oxygen concentration. The hydrogen distribution is almost the same in Figures $5(\mathrm{a})-5(\mathrm{~d})$. It is shown that the gap size and the wave number do not affect the distribution of the hydrogen. The air (or oxygen) distribution is more important than the hydrogen, and the anode channel can keep the straight channel. By contrast, the waved gas flow channel achieves higher oxygen and hydrogen transfer rates in the reaction surface region since transport is achieved by stronger convection.

5.3. Polarization Curve. The polarization characteristics of a PEMFC for the different gas flow channels show the meanings of evaluating the performance of the fuel cell. The numerical simulation was verified by $\mathrm{Hu}$ et al. [20] as in Figure 6. The numerical results comparing the experimental data are reasonable. It displays the polarization and power density 


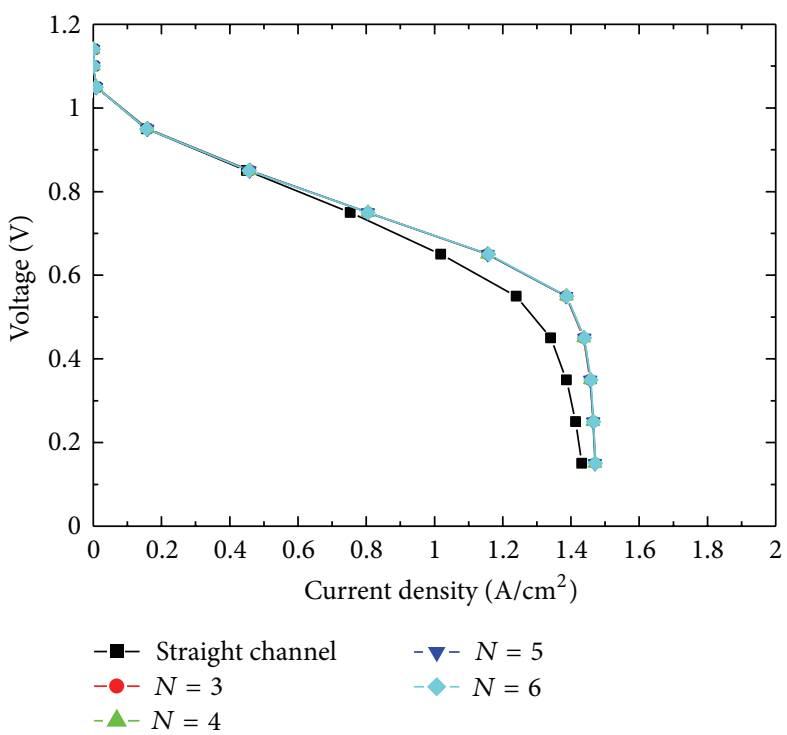

(a)

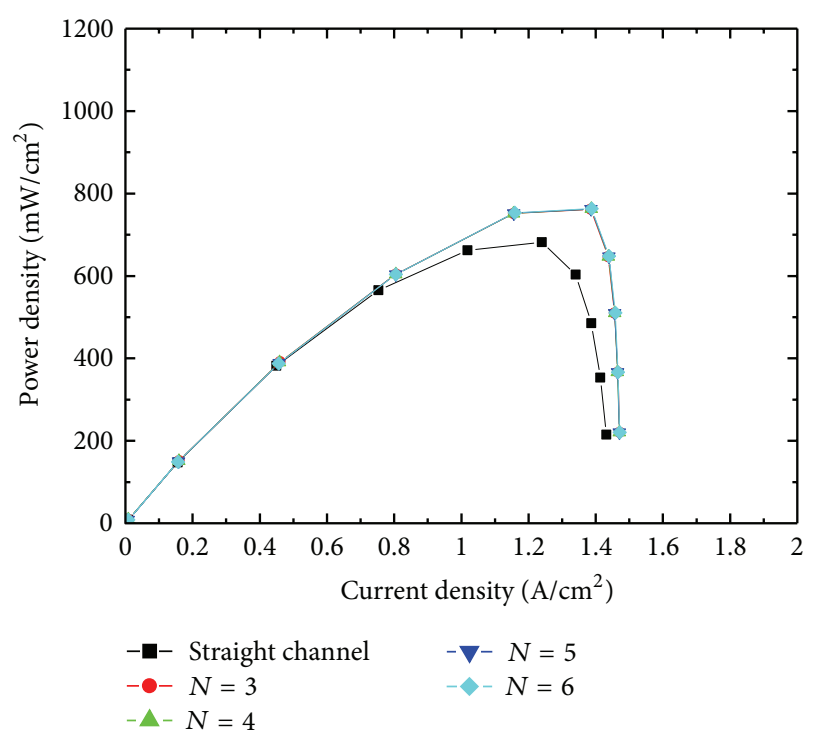

(b)

Figure 12: (a) Polarization curve and (b) power density curve in the waved gas flow channel for the different wave numbers at lower velocity.

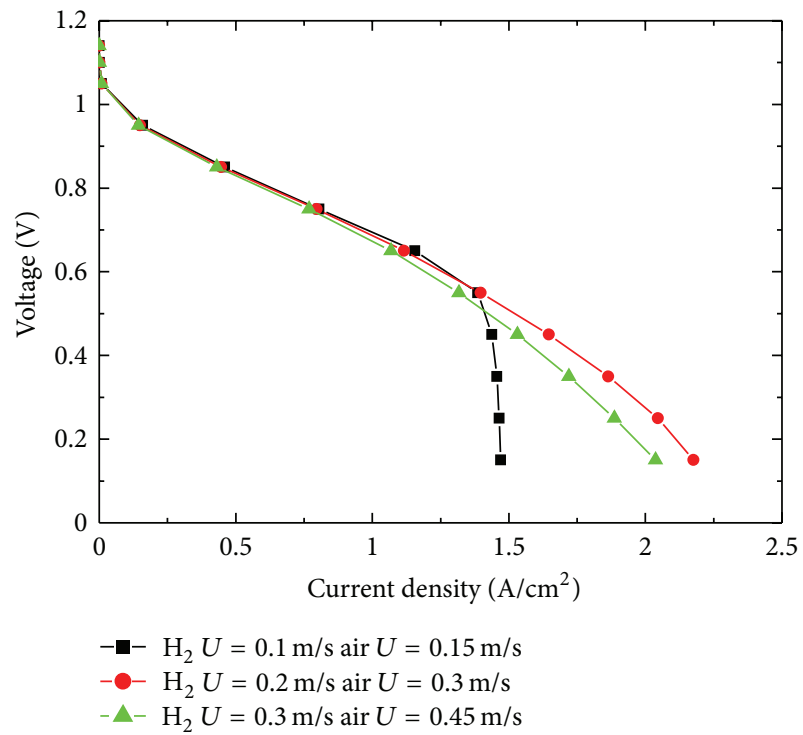

(a)

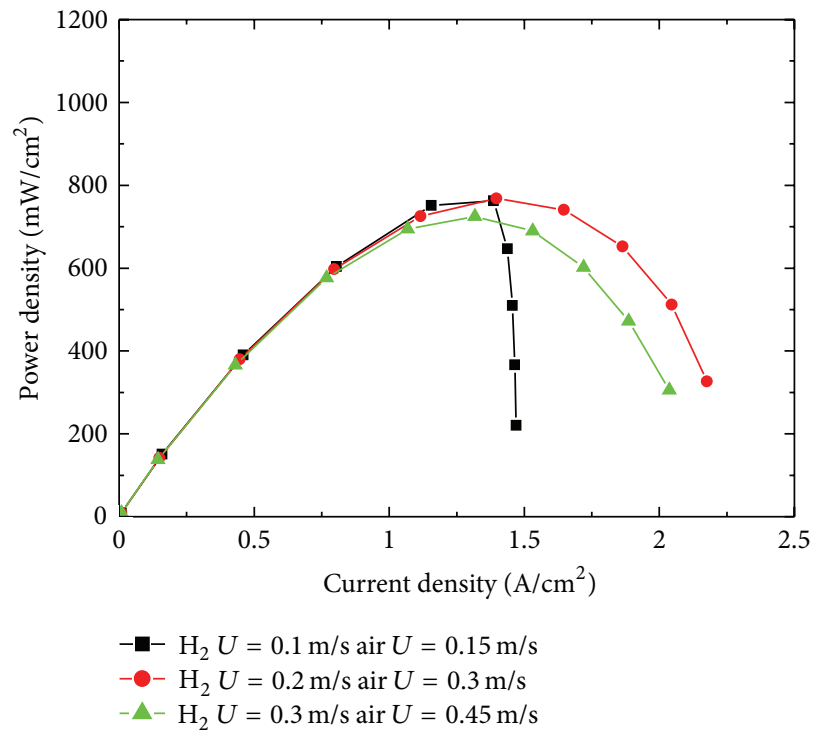

(b)

FIgure 13: (a) Polarization curve and (b) power density curve in the waved gas flow channels at constant velocity ratio (4-wave gap $=0.1)$.

curves of PEMFCs with the different gap ratios in the waved flow channels. The inlet velocities in the anode and cathode are $0.2 \mathrm{~m} / \mathrm{s}$ for hydrogen and $0.3 \mathrm{~m} / \mathrm{s}$ for air. It is shown that the gap ratio is an important variable. The waved channel design can increase the performance of the fuel cell. As the gap ratio becomes greater than 0.5 , the effect is more obvious. The results also show that the power density of the PEMFC with the waved channel is $30 \%$ higher than that with the straight channel. When the inlet velocity decreases one-half, the performance of PEMFC decays and the reactant gas is not enough at the lower operating velocity, and that causes the performance to drop suddenly at the curved end, as in Figure 7. The drop shows that the reactant lacks the gas at the lower operating voltage. Figures 8,9 , and 10 which change wave number and gap size represent the effect from the different air velocities and the constant hydrogen velocity. The air velocities are $0.3,0.4,0.5$, and $0.6 \mathrm{~m} / \mathrm{s}$. It is shown that the performance decays as the air velocity increases. The reason is that the high velocity sharply reduces the effect of the force convection, and most of the gas flows out directly. The waved number seems to have no effect on the performance. Compare Figures 8 and 10, and we can find that the changes of characteristics are not conspicuous. Figures 11 and 12 represent the performance for the different wave 


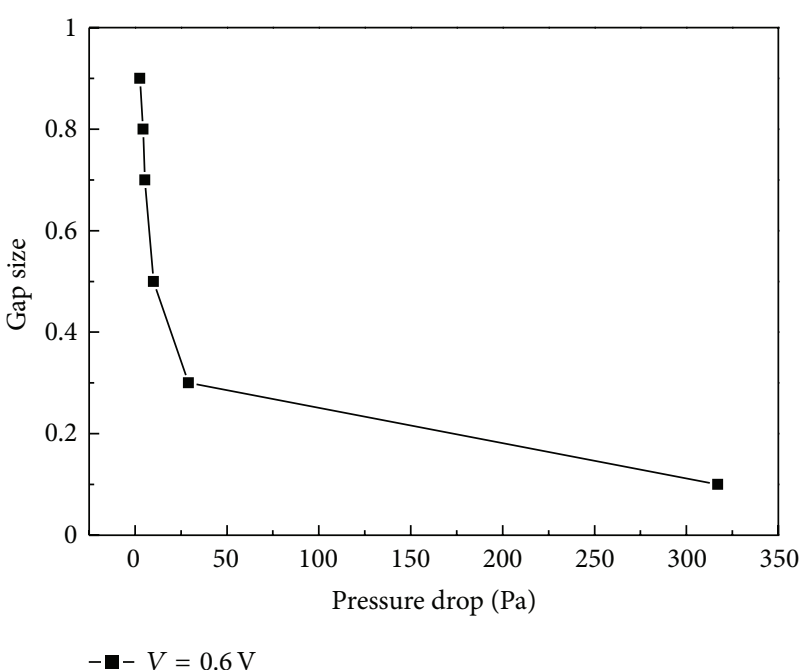

(a)

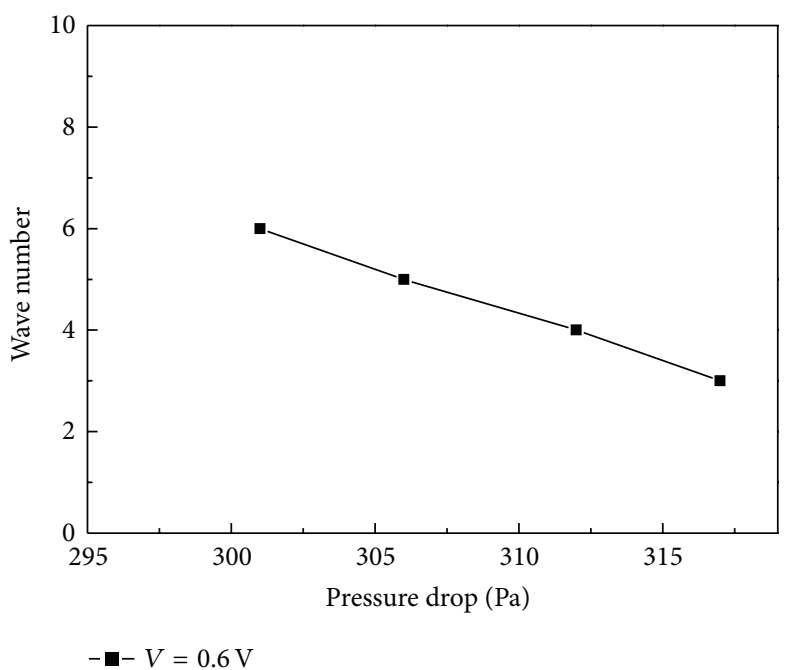

(b)

FIGURE 14: Effects of (a) the gap size and (b) the wave number on the pressure drop at the cathode.

numbers and different flow velocities. The performance is the same for the different wave numbers in the flow channel at higher velocity, and is better than the straight flow channel, as Figure 11. We can find the waved design is overspread in the flow channel, and the area that pushes the flow gas into the GDL is equal for the different wave number in the flow channel. Therefore, the effect of the force convection is alike. Figure 12 shows the same condition, but the velocity is only one-half. At a constant ratio 3/2 for the air and hydrogen velocities, a hydrogen inlet velocity of $0.2 \mathrm{~m} / \mathrm{s}$ yields a higher cell voltage and power density, as in Figure 13. A hydrogen inlet velocity of $0.3 \mathrm{~m} / \mathrm{s}$ has a relatively poorer performance, but the performance for the hydrogen inlet velocity of $0.1 \mathrm{~m} / \mathrm{s}$ results in a drop at the voltage of $0.5 \sim 0.6 \mathrm{~V}$ because of the insufficient hydrogen.

5.4. Pressure Drop. Figure 14 shows the effect of the gap size and wave number on the cathode pressure drop in the cells with wavy channel design. Figure 14(a) indicates that the pressure drops depend strongly on the gap size of flow channel. As the gap size decreases, the pressure drops increased acutely. Figure 14(b) shows the effect of the wave number. The pressure drop decreases slightly following the wave number increases. The overall effect for the shape factor is similar in the continuous waved flow channel for the different wave number. The effect of the wave number for the pressure drop is not clearly in the continuous waved flow channel design. Therefore, the wavy channel designs whose gap size is larger than 0.3 has a reasonable pressure drop, and the effect of the wave number is not significant.

This result demonstrates that the waved flow channel affects the reactant gas transport to the catalyst layer by a convection mechanism. This new style flow channel design enhances the performance through the forced convection. The effect improves electrical performance significantly.

\section{Conclusions}

This study researched the effect of the gas transport and the performance of the PEMFCs with the waved gas flow channels compared to the straight gas flow channels. The gas flow velocity, the reactant gas concentration, and the performance in the fuel cell have been examined. The results show that the new style channel provides a better transport mechanism and improves the performance characteristics. It is showed that the waved flow channels enhanced a forced convection performance. The characteristics of the transport mechanism are more significant for the small gap size, and the limit gap size between the GDL and the bipolar plate in the waved channel is about 0.5 . The velocity of the flow channel has a limit. The performance is decreased by a higher velocity. The different wave number affects the performance inconspicuously, and this is because the integral extruding area is not different in the continuous waved design. The pressure drop is increased as the gap size decreases and the wave number decreases. The larger gap size $(\delta>0.3)$ has a reasonable pressure drop. Furthermore, the waved gas flow channel enhances the transport mechanism and improves the polarization characteristics and the power density.

\section{Nomenclature}

C: Mass fraction

$C_{F}$ : Quadratic drag factor

D: Mass diffusion $\left(\mathrm{m}^{2} / \mathrm{s}\right)$

d: Gap height ( $\mathrm{mm})$

F: Faraday's constant $(96,485 \mathrm{C} / \mathrm{mol})$

$H$ : Flow channel height $(\mathrm{mm})$

I: $\quad$ Current density $\left(\mathrm{A} / \mathrm{m}^{2}\right)$

$j: \quad$ Transfer current density $\left(\mathrm{A} / \mathrm{m}^{-3}\right)$

$k_{m}^{\text {eff }}$ : Effective ionic conductivity of membrane $(\mathrm{S} / \mathrm{cm})$ 


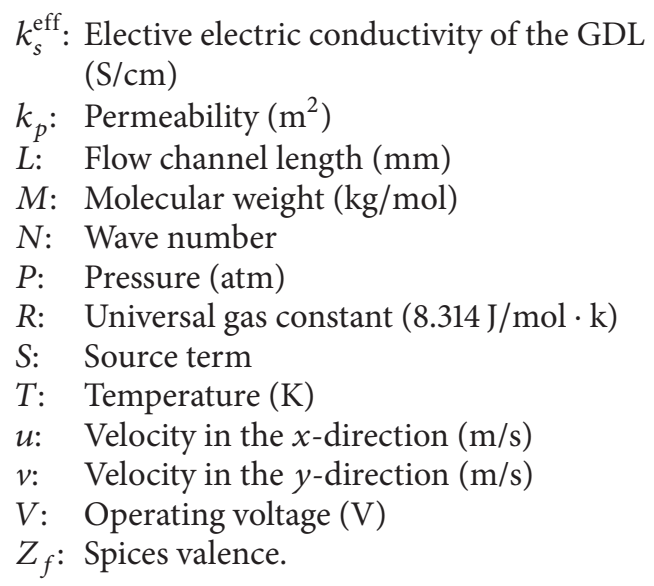

\section{Greek Symbols}

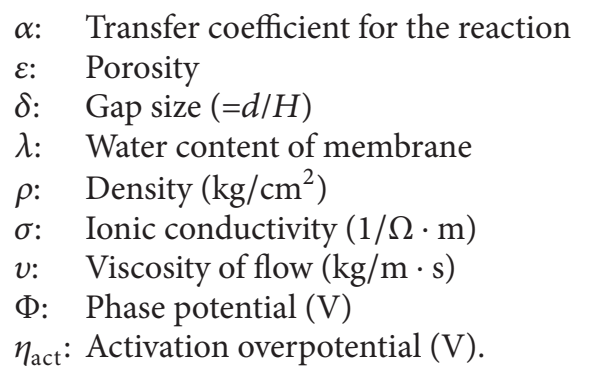

\section{Subscripts}

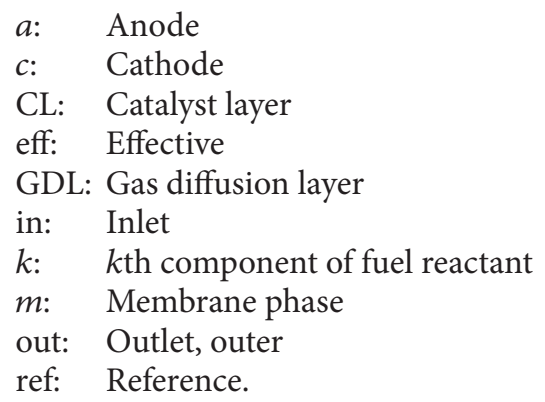

\section{Acknowledgment}

The authors would like to thank the National Science Council of China for supporting this project under Contract no. NSC99-2221-E-006-165-MY3.

\section{References}

[1] S. Um and C. Y. Wang, "Three-dimensional analysis of transport and reaction in proton exchange membrane fuel cells," in Proceedings of the ASME International Mechanical Engineering Congress \& Exposition, Walt Disney World Dolphin, Orlando, Fla, USA, November 2000.

[2] S. Um and C. Y. Wang, "Three-dimensional analysis of transport and electrochemical reactions in polymer electrolyte fuel cells," Journal of Power Sources, vol. 125, no. 1, pp. 40-51, 2004.
[3] T. V. Nguyen, "A gas distributor design for proton-exchangemembrane fuel cells," Journal of the Electrochemical Society, vol. 143, no. 5, pp. L103-L105, 1996.

[4] K. Tüber, A. Oedegaard, M. Hermann, and C. Hebling, "Investigation of fractal flow-fields in portable proton exchange membrane and direct methanol fuel cells," Journal of Power Sources, vol. 131, no. 1-2, pp. 175-181, 2004.

[5] W. He, J. S. Yi, and T. Van Nguyen, "Two-phase flow model of the cathode of PEM fuel cells using interdigitated flow fields," AIChE Journal, vol. 46, no. 10, pp. 2053-2064, 2000.

[6] F. B. Weng, A. Su, G. B. Jung, Y. C. Chiu, and S. H. Chan, "Numerical prediction of concentration and current distributions in PEMFC," Journal of Power Sources, vol. 145, no. 2, pp. 546-554, 2005.

[7] P. T. Nguyen, T. Berning, and N. Djilali, "Computational model of a PEM fuel cell with serpentine gas flow channels," Journal of Power Sources, vol. 130, no. 1-2, pp. 149-157, 2004.

[8] J. J. Hwang, C. K. Chen, R. F. Savinell, C. C. Liu, and J. Wainright, "A three-dimensional numerical simulation of the transport phenomena in the cathodic side of a PEMFC," Journal of Applied Electrochemistry, vol. 34, no. 2, pp. 217-224, 2004.

[9] W. M. Yan, S. C. Mei, C. Y. Soong, Z. S. Liu, and D. Song, "Experimental study on the performance of PEM fuel cells with interdigitated flow channels," Journal of Power Sources, vol. 160, no. 1, pp. 116-122, 2006.

[10] W. M. Yan, C. Y. Chen, S. C. Mei, C. Y. Soong, and F. Chen, "Effects of operating conditions on cell performance of PEM fuel cells with conventional or interdigitated flow field," Journal of Power Sources, vol. 162, no. 2, pp. 1157-1164, 2006.

[11] J. Park and X. Li, "An experimental and numerical investigation on the cross flow through gas diffusion layer in a PEM fuel cell with a serpentine flow channel," Journal of Power Sources, vol. 163, no. 2, pp. 853-863, 2007.

[12] X. D. Wang, Y. Y. Duan, and W. M. Yan, "Numerical study of cell performance and local transport phenomena in PEM fuel cells with various flow channel area ratios," Journal of Power Sources, vol. 172, no. 1, pp. 265-277, 2007.

[13] H. C. Liu, W. M. Yan, C. Y. Soong, and F. Chen, "Effects of baffle-blocked flow channel on reactant transport and cell performance of a proton exchange membrane fuel cell," Journal of Power Sources, vol. 142, no. 1-2, pp. 125-133, 2005.

[14] C. Y. Soong, W. M. Yan, C. Y. Tseng, H. C. Liu, F. Chen, and H. S. $\mathrm{Chu}$, "Analysis of reactant gas transport in a PEM fuel cell with partially blocked fuel flow channels," Journal of Power Sources, vol. 143, no. 1-2, pp. 36-47, 2005.

[15] J. K. Kuo and C. K. Chen, "A novel Nylon-6-S316L fiber compound material for injection molded PEM fuel cell bipolar plates," Journal of Power Sources, vol. 162, no. 1, pp. 207-214, 2006.

[16] J. K. Kuo and C. K. Chen, "Evaluating the enhanced performance of a novel wave-like form gas flow channel in the PEMFC using the field synergy principle," Journal of Power Sources, vol. 162 , no. 2, pp. 1122-1129, 2006.

[17] J. K. Kuo and C. K. Chen, "The effects of buoyancy on the performance of a PEM fuel cell with a wave-like gas flow channel design by numerical investigation," International Journal of Heat and Mass Transfer, vol. 50, no. 21-22, pp. 4166-4179, 2007.

[18] M. G. Santarelli and M. F. Torchio, "Experimental analysis of the effects of the operating variables on the performance of a single PEMFC," Energy Conversion and Management, vol. 48, no. 1, pp. 40-51, 2007. 
[19] M. Hu, A. Gu, M. Wang, X. Zhu, and L. Yu, “Three dimensional, two phase flow mathematical model for PEM fuel cell-part I: model development," Energy Conversion and Management, vol. 45, no. 11-12, pp. 1861-1882, 2004.

[20] M. Hu, X. Zhu, M. Wang, A. Gu, and L. Yu, "Three dimensional, two phase flow mathematical model for PEM fuel cell-part II: analysis and discussion of the internal transport mechanisms," Energy Conversion and Management, vol. 45, no. 11-12, pp. 18331916, 2004.

[21] S. S. Hsieh, S. H. Yang, J. K. Kuo, C. F. Huang, and H. H. Tsai, "Study of operational parameters on the performance of micro PEMFCs with different flow fields," Energy Conversion and Management, vol. 47, no. 13-14, pp. 1868-1878, 2006.

[22] G. Prentice, Electrochemical Engineering Principles, Prentice Hall International, Houston, Tex, USA, 1991.

[23] T. E. Springer, T. A. Zawodzinski, and S. Gottsfeld, "Polymer electrolyte fuel cell model," Journal of the Electrochemical Society, vol. 150, pp. 2334-2341, 2003.

[24] S. V. Patankar, Numerical Heat Transfer, Hemisphere, Washington, DC, USA, 1980. 


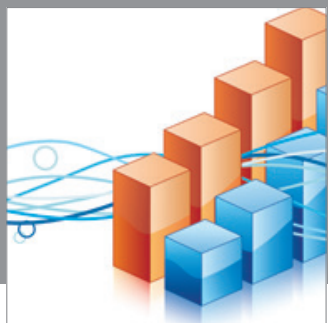

Advances in

Operations Research

mansans

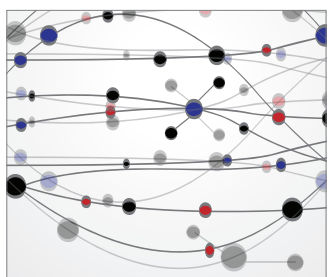

The Scientific World Journal
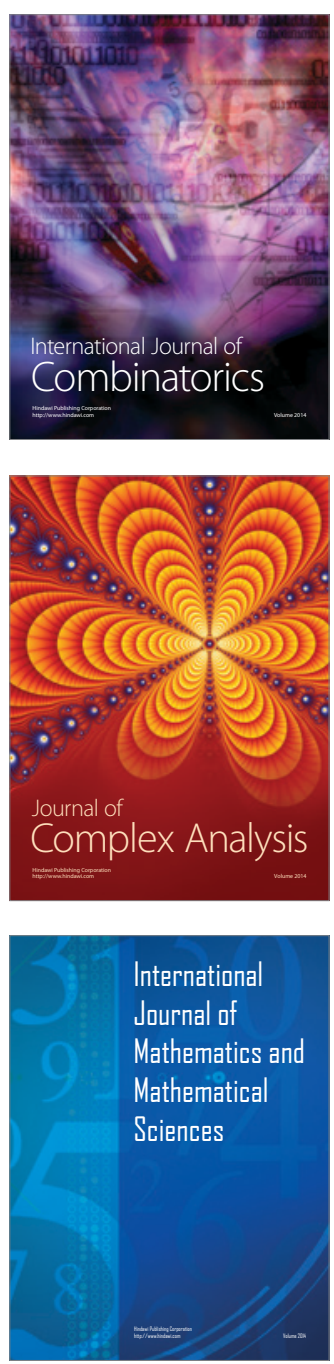
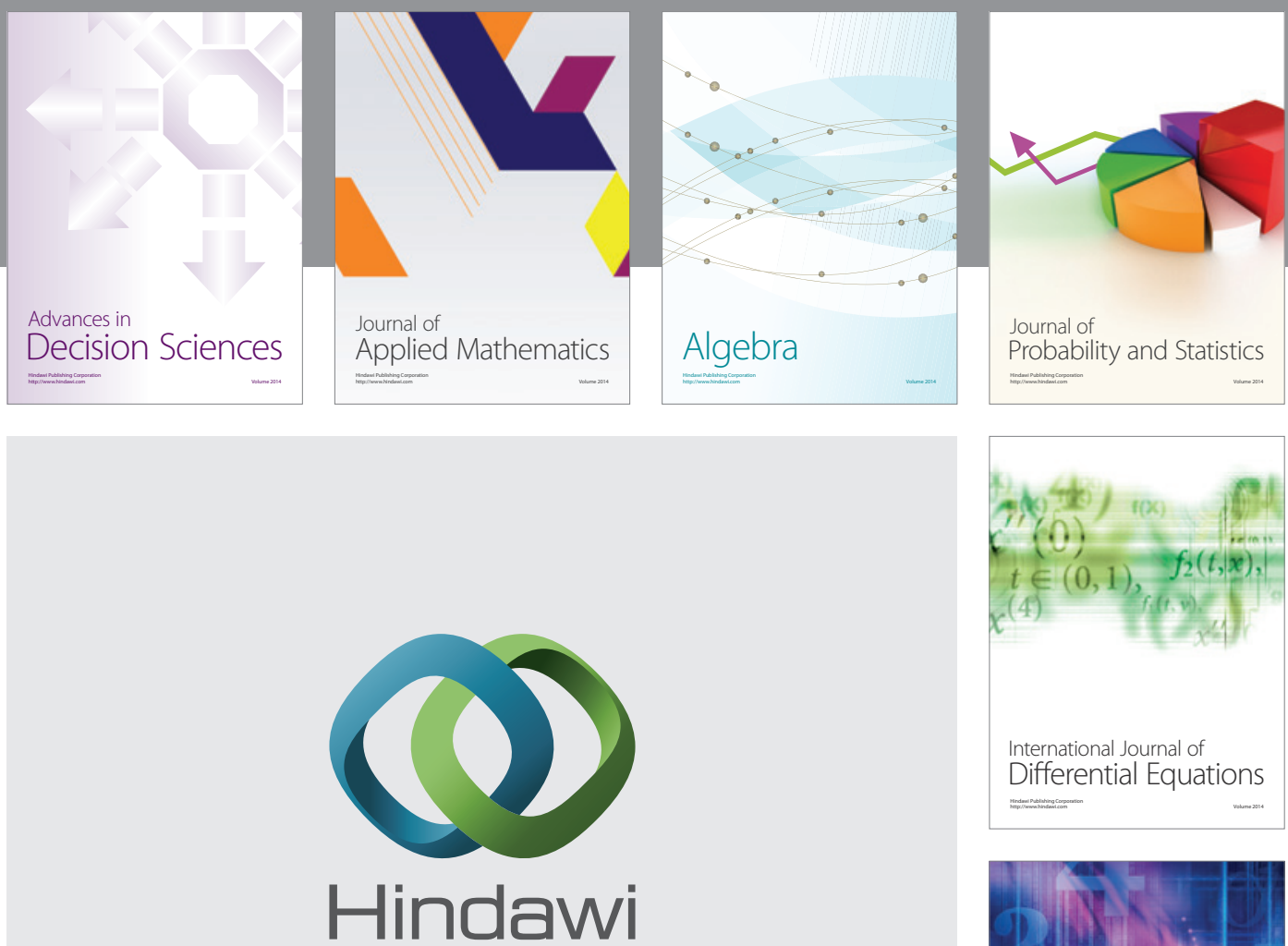

Submit your manuscripts at http://www.hindawi.com
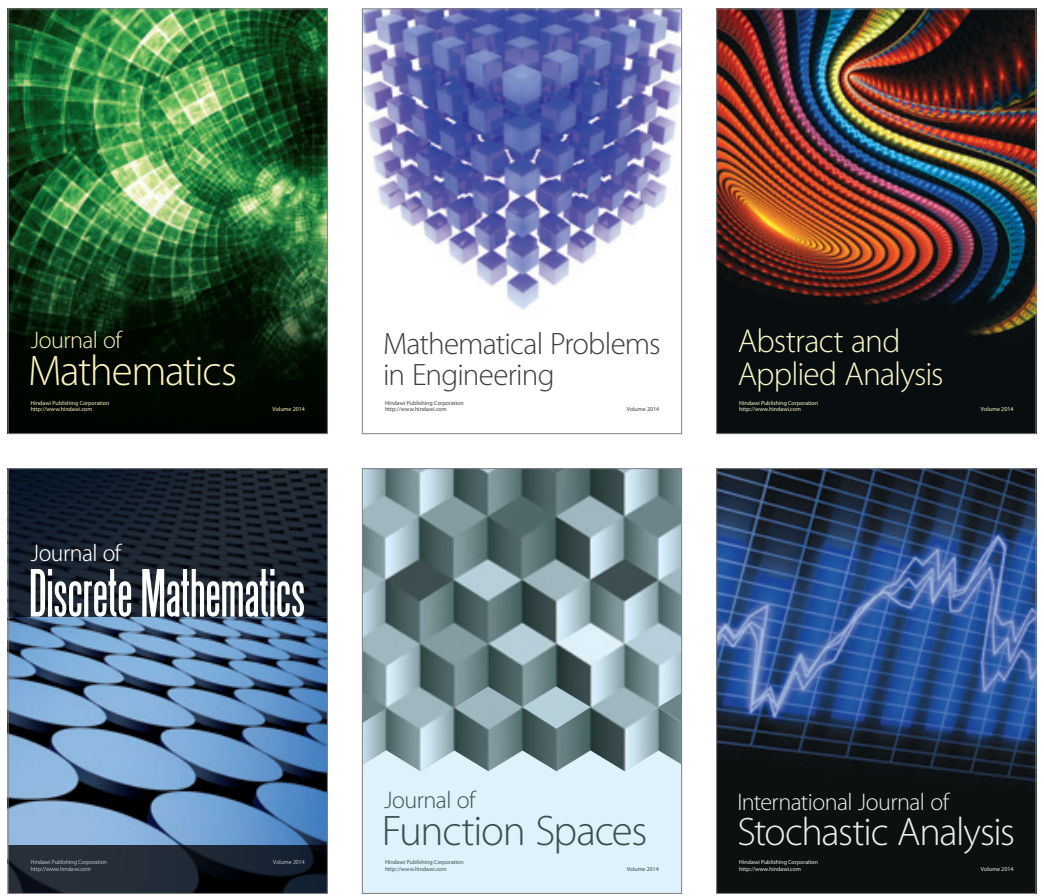

Journal of

Function Spaces

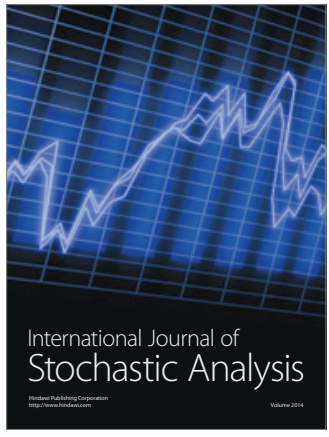

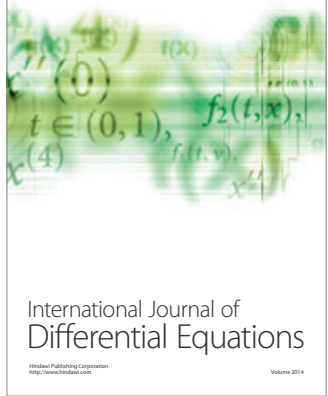
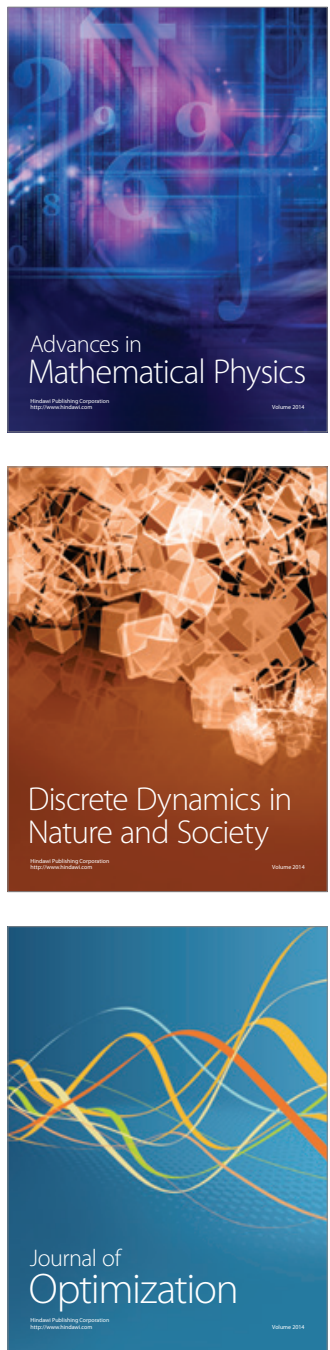